\title{
Gene and protein expression in the myometrium in pregnancy and labor
}

\author{
Michelle Breuiller-Fouche ${ }^{1}$ and Guy Germain ${ }^{2}$ \\ ${ }^{1}$ Institut National de la Santé et de la Recherche Médicale, Unité 767, Paris, F-75014, France and ${ }^{2}$ Institut National \\ de la Recherche Agronomique, Biologie du Développement et Reproduction, Centre de Recherches de Jouy, \\ Jouy-en-Josas, F-78352, France
}

Correspondence should be addressed to G Germain; Email guy.germain@jouy.inra.fr

\begin{abstract}
Microarray technologies widen our comprehension of the major structural and metabolic transformations which affect the myometrium from the very beginning of pregnancy until parturition. The results are coherent with the mass of information which was accumulated previously, primarily on the basis of studies of selected critical factors. They highlight the activation of precise signaling pathways, some of which may have been previously under evaluated. The remodelling and maturation processes that the myometrium undergoes in pregnancy appear clearly as phenomena which last during the full course of gestation. Comparatively, the onset of labor is perhaps the phenomenon which remains the least well described by these methods of analysis. Nevertheless, genomic studies constitute a necessary first step of orientation and help establishing new links between the generic signaling pathways that are activated during the normal or pathological gestation. These studies also represent an indicative step that will have to be paralleled, in the future, with the results of the systematic proteomic analysis of the myometrium.

Reproduction (2006) $131837-850$
\end{abstract}

\section{Introduction}

Parturition encompasses composite physiological processes that require synchronization of uterine contractions, cervical dilatation and fetal membrane rupture. The mechanisms by which parturition is triggered remain unknown, but they as are all developmental processes, the results of timely coordinated biochemical and physiological steps. Over the past decades, reductionist approaches have investigated the cellular and molecular bases of these developmental changes and focused on assessing the regulation of selected critical factors involved in the onset of labor.

Recently, the near-entire genomic sequence of the human and several model animals have provided the opportunity to enhance our understanding of the relationships between genes, phenotypes and global transcriptional status. Oligonucleotides or DNA microarray technologies allow the examination of the function of thousands of genes at once and in parallel, thereby providing an 'assay' of the transcriptional status of cells or tissues in a wide variety of physiological or pathophysiological situations (Dunckley et al. 2005). In the context of uncomplicated or complicated pregnancy and parturition, their interest is to obtain a molecular snapshot of the expression profile of gene transcripts as a function of the time-dependent process regulating myometrial activity.

\section{Functional genomic studies during pregnancy}

Functional genomics has arrived at the study of parturition in different species: mice (Bethin et al. 2003, Salomonis et al. 2005); rats (Girotti \& Zingg 2003) and humans (Chan et al. 2002, Marvin et al. 2002a, 2002b, Tashima et al. 2002, Bethin et al. 2003, Charpigny et al. 2003, Keelan et al. 2003, Bailey et al. 2005, Esplin et al. 2005, Havelock et al. 2005). Also in different tissues: myometrium (Aguan et al. 2000, Chan et al. 2002, Bethin et al. 2003, Charpigny et al. 2003, Esplin et al. 2005, Havelock et al. 2005, Salomonis et al. 2005); primary cultures of human myometrial cells (Bailey et al. 2005); fetal membranes (Muhle et al. 2001, Chen et al. 2002, Marvin et al. 2002a, 2002b, Tashima et al. 2002, Keelan et al. 2003) and trophoblasts (Chen et al. 2002, Kato et al. 2002). Various methodologies have been used: suppression subtractive hybridization (SSH) (Chan et al. 2002) or microarrays for most of the previous cited studies. All investigators have reported genes differentially regulated 
during parturition (Romero et al. 2002) and multiple novel candidate markers for preterm labor (Wu et al. 1999, Chan et al. 2002, Marvin et al. 2002a, 2002b). They contributed to shed light on specific pathophysiological issues such as the patterns of expression of cytokines in the fetal membranes and decidua particularly in the presence of intrauterine infection (Keelan et al. 2003) or on the induction of enzymes for prostaglandin synthesis (Bethin et al. 2003) which are commonly associated with the onset of labor. Groups of genes with as yet unknown functional connection to these pathologies were also found coordinately expressed. This was emphasized in animal studies which allow the exploration of global gene expression patterns and their co-regulation on the basis of their genomic location over the full time-course of myometrial transformation (i.e. pregnancy), following experimentallycontrolled infection (Wu et al. 1999, Muhle et al. 2001, Girotti \& Zingg 2003, Salomonis et al. 2005) or in human studies following transfection of cultured myometrial cells with CREB, CREMalpha and CREMtau2alpha CDNAs, to affect the expression of genes (Bailey et al. 2005).

Computational methods have significantly helped to the interpretation of gene profiling experiments by delineating clusters of genes sharing coherent expression features (Claverie 1999). During the last five years, statistical methods and data analysis for array studies have progressed enormously and today an 'ideal' study should now incorporate i) careful research designs (differential expression or cross sectional studies), ii) statistical methods incorporating background adjustment and normalization of data, assessment of differential expression after determining sample size to control the proportion of positive calls that are false positives (false discovery rate), iii) hierarchical clustering (e.g. HOPACH method; Ganesh et al. 2004, Salomonis et al. 2005), iv) functional organization of genes into pathways or networks with the aid of integrated databases like the gene ontology consortium (Lewis 2005) or the Kyoto encyclopedia of genes and genomes (KEGG; Kanehisa 1997, Kanehisa \& Goto 2000) and finally $v$ ) integrating genotype, transcription and clinical trait data (Salomonis et al. 2005).

The past studies on the human myometrium have reported on different microarrays which contained different sets of genes/expressed sequence tags (ESTs) and each study has profiled a small number of patients due to various constraints. More gene expression profiling information would be a welcome addition to our knowledge base of parturition. The present review examines transcriptional differences between the preterm quiescent myometrium, term myometrium not in labor and term myometrium in labor. Attention is focused on genes expressed essentially in the 'normal' human myometrium. From identified genes that were differentially expressed, we identified biological pathways based on these genes. One study has reported a direct comparison of the nonpregnant myometrium (NP) with the pregnant human myometrium at term not in labor (TNIL; Rehman et al.
2003). It gives an overall picture of the changes that the uterine muscle undergoes in its adaptation to gestation. Two studies have described the changes in gene expression in the myometrium in preterm patients not in labor (PTNIL) versus patients at TNIL (Bethin et al. 2003, Charpigny et al. 2003) and two additional studies have described the changes in gene expression in the myometrium in patients at TNIL versus patients at term in labor (TIL) (Esplin et al. 2005, Havelock et al. 2005). Other studies could not be compiled directly, either because they did not provide sufficient information on the genes being studied (i.e. lack of GenBank or Unigene references), they considered other components of the uterofetal unit (i.e. membranes, decidua, cervix, etc.) or they were carried out on animal species.

To translate lists of tens or hundreds of genes found to be differentially regulated in the conditions under study into a clearer understanding of the biological phenomena involved, we used combinations of searches through the literature referenced in public databases and the Onto-Tools software developed by the Draghici's group at Wayne State University, (Detroit, MI, USA; http://vortex. cs.wayne.edu/Projects.html). The Onto-Express module helps to recognize functional profiles (using gene ontology terms) for the categories: biochemical function; biological process; cellular role; cellular component; molecular function, and chromosome location (Draghici et al. 2003). The Pathway-Express module helps data mining - proposing on the basis of a computational method a hierarchical list of several KEGG pathways (Kanehisa 1997, Kanehisa \& Goto 2000) most likely adjusted to changes observed in microarray experiments (Khatri et al. 2005). KEGG is a knowledge base for systematic analysis of gene functions, linking genomic information with higher order functional information (http://www.genome.jp/kegg/pathway.html). Because relevant raw data for myometrium microarrays were not always available, input data files for use with the Onto-Tools software modules were built on gene lists reported in published papers or, when available, on the complete gene expression data set, deposited as supplemental data at a public Internet site, see Bethin et al. 2003, Charpigny et al. 2003, Rehman et al. 2003. Drawbacks and limitations inherent to the use of Onto-Tools or of their cognate alternatives for ontological analysis, have been reviewed (Khatri \& Draghici 2005). These limitations remain to the present day, questions over the robustness of array data and the criteria under which their conclusions were drawn have been made. How can one compare the reproducibility of data on two or more different array platforms or between laboratories using the same or different array platforms? Are there groups of genes that one can almost use as quality controllers for gestational changes? The recent review by Allison et al. (2006) has the merit not of providing definitive answers on these questions but of proposing simple sound recommendations for future microarrays analysis methods. 
In the pregnant human myometrium, the differential expression of 118 genes could be dispatched in 14 main KEGG pathways that are the most representative (see Khatri et al. 2005, for the rationale of KEGG pathway search) of the changes seen in NP versus TNIL, PTNIL versus TNIL, and TNIL versus TIL. However, other genes not identified here may be involved in known pathways with importance in myometrial functions, because the KEGG itself is permanently evolving, the functions of many genes are yet to be defined under various contexts and arrays used in the referred studies may not have contained all known genes listed in the KEGG base. Tables 1-4 and Figs 1-2 summarize the compiled data which are commented on below in more detail. Because our discussion is also largely drawn from literature reports of relevant protein changes in human and other animal species, as well as in model cell culture systems, mention of the species or model systems is made from which we quoted this supplementary data. Wherever possible, OMIM nomenclature has been adopted in the text and tables (http://www.ncbi.nlm.nih.gov/omim/).

\section{Changes in structural and contractile genes during gestation}

Actin cytoskeleton, focal adhesion, adherens and tight junction related genes represent a large subset of genes that are over-expressed in the pregnant human myometrium as compared to the non-pregnant state (Table 1).

\section{Regulation of actin cytoskeleton}

Growth and cytoskeletal remodeling of myometrial cells during pregnancy are critical for myometrial functions including those expressed during labor and delivery. At term, signals that initiate labor, ultimately promote a switch in the phenotype of the quiescent uterus to a smooth muscle which becomes spontaneously active, excitable, highly responsive to uterine agonists, and exhibits a high degree of cell-cell coupling. Myometrial cells are rich in actin microfilaments, intermediate filaments and microtubules that allow cells to adapt to a variety of shapes and to carry out coordinated and directed movements. In rat, myometrial expression of alpha-actin is high throughout pregnancy. An increased expression of gamma-actin and its translocation to the membrane is observed in uterine myocytes at late gestation. Therefore, the alteration in myometrial composition of contractile proteins is important to prepare the myometrium for the development of contractions during labor (Shynlova et al. 2005).

RhoA, a member of the Ras superfamily, and its downstream mediator RhoA kinase (ROCK1) are necessary for agonist-induced stress fiber formation in human myometrial cells (Gogarten et al. 2001). The higher expression of protein kinase $\mathrm{C}$ (PKC) isoforms observed in pregnant versus non-pregnant myometrium (Rehman et al. 2003) may promote or drive the formation of stress fibers.
Additionally, up-regulation of ROCK1 has been demonstrated in human term myometrium (Moore et al. 2000, Rehman et al. 2003). This leads to the idea that increased endogenous ROCK1 activity, resulting in enhanced RhoAmediated calcium sensitization, is involved in the increased contractility at the time of labor. It is of note that epidermal growth factor (EGF) increases the presence of actin and myometrial EGF receptor transcripts are increased at the time of parturition in humans (Gargiulo et al. 1997, Charpigny et al. 2003, Rehman et al. 2003).

\section{Focal adhesion, adherens junctions and tight junctions}

The transmission of force between the contractile apparatus of the cell and extracellular matrix (ECM) occurs at membrane-associated dense plaques or 'focal adhesions'. The homeostasis of ECM relies upon the intricate interactions between collagens (ECM components), integrins and the associated signaling molecules (focal adhesion molecules). This in turn regulates adherens and tight junction dynamics. Focal adhesions consist of clusters of integrins that mediate interactions between the extra- and intra-cellular environments. The cytoplasmic regions of integrins connect with cytoskeletal elements and signaling components such as focal adhesion kinase (FAK), while the extracellular regions connect to specific extracellular matrix molecules such as collagen, laminin or fibronectin.

Fetal growth imposes mechanical tension on the myometrium at term, which in turn induces activation of FAK leading to focal adhesion turnover and supporting myometrial cell hypertrophy. During late pregnancy, a fall in tyrosine phosphorylation of FAK and stabilization of focal adhesions occur for provoking the cessation of myometrial hypertrophy. Because actin polymerization and the dynamic remodeling of the actin cytoskeleton play key roles in the regulation of myometrial contraction, there is growing evidence that stretching induces labor, probably through a change in the expression of contraction associated proteins (CAPs) as observed in rat myometrium (Macphee \& Lye 2000). In human term pregnant myometrium, changes in cytoskeletal organization support a role for FAK and other focal adhesion-associated proteins as regulators of actin dynamics. Fibronectin receptor-alpha subunit (ITGA5) with its known partner ITGB1, is up-regulated in rat myometrium during late pregnancy and labor (Williams et al. 2005) as well as vitronectin receptoralpha polypeptide (ITGAV) in the TNIL human myometrium (Rehman et al. 2003). Therefore they may interact with actin-binding proteins (e.g. actinin and filamin) to form mechanical links to the cytoskeleton. A strong expression of vinculin is concentrated at actin-vinculin focal adhesion sites in human myometrial cells ( $Y u$ \& Lopez Bernal 1998). At the time of parturition, expression of integrins declines and the focal adhesion and related pathways do not change in studies which compare the TNIL and TIL states of pregnancy (see Table 1). 


\begin{tabular}{|c|c|c|c|c|c|c|c|c|c|c|c|}
\hline \multicolumn{3}{|c|}{ Actin cytoskeleton } & \multicolumn{3}{|c|}{ Focal adhesion } & \multicolumn{3}{|c|}{ Adherenes junctions } & \multicolumn{3}{|c|}{ Tight junctions } \\
\hline $\begin{array}{l}\text { NP-TNIL }{ }^{1} \\
(15)\end{array}$ & $\begin{array}{c}\text { PTNIL-TNIL }^{2} \\
\text { (6) }\end{array}$ & $\begin{array}{c}\text { TNIL-TIL } \\
(0)\end{array}$ & $\begin{array}{c}\mathrm{NP}-\mathrm{TNIL}^{1} \\
(18)\end{array}$ & $\begin{array}{c}\text { PTNIL-TNIL }{ }^{2} \\
\text { (6) }\end{array}$ & $\begin{array}{c}\text { TNIL-TIL }{ }^{3} \\
\text { (3) }\end{array}$ & $\begin{array}{c}\mathrm{NP}-\mathrm{TNIL}^{3} \\
(11)\end{array}$ & $\begin{array}{c}\text { PTNIL-TNIL }{ }^{2} \\
\text { (3) }\end{array}$ & $\begin{array}{c}\text { TNIL-TIL }{ }^{3} \\
(0)\end{array}$ & $\begin{array}{c}\text { NP-TNIL }{ }^{1} \\
\text { (10) }\end{array}$ & $\begin{array}{c}\text { PTNIL-TNIL }{ }^{2} \\
(0)\end{array}$ & $\begin{array}{c}\text { TNIL-TIL }^{3} \\
(0)\end{array}$ \\
\hline $\begin{array}{l}\text { ACTN4(+) } \\
\text { CD14(+) } \\
\text { EGFR(+) } \\
\text { FGFR1(+) } \\
\text { HEM1(+) } \\
\text { ITGAM(+) } \\
\text { ITGAV(+) } \\
\text { ITGB5(+) } \\
\text { PFN1(+) } \\
\text { PIK3CA(+) } \\
\text { PIP5K1C(+) } \\
\text { RAC2(+) } \\
\text { ROCK1(+) } \\
\text { RRAS (+) } \\
\text { VCL (+) }\end{array}$ & $\begin{array}{l}\text { EGF }(-) \\
\text { ITGAV }(-) \\
\text { ITGB3(-) } \\
\text { ITGB6(-) } \\
\text { MATK(-) } \\
\text { PIK3CB }(-)\end{array}$ & & $\begin{array}{l}\text { ACTN4(+) } \\
\text { ARHGAP5 }(+) \\
\text { CAV2(+) } \\
\text { COL1A2(+) } \\
\text { EGFR(+) } \\
\text { FLNA(+) } \\
\text { ITGB5(+) } \\
\text { PIK3CA (+) } \\
\text { PIP5K1C(+) } \\
\text { PRKCB1(+) } \\
\text { PRKCG(+) } \\
\text { ROCK1(+) } \\
\text { RRAS(+) } \\
\text { TNC(+) } \\
\text { VASP(+) } \\
\text { VCL(+) } \\
\text { VWF(+) } \\
\text { ZYX (+) }\end{array}$ & $\begin{array}{l}\text { INSR(+) } \\
\text { ITGB3(-) } \\
\text { ITGB6(-) } \\
\text { MAPK10(-) } \\
\text { PIK3CB(-) } \\
\text { RAP1A(-) }\end{array}$ & $\begin{array}{l}\text { ILK(+) } \\
\text { THBS1(+) } \\
\text { TNC }(+)\end{array}$ & $\begin{array}{l}\text { ACTN4(+) } \\
\text { CTNNA1(+) } \\
\text { EGFR }(+) \\
\text { FGFR1(+) } \\
\text { NLK(+) } \\
\text { PTPN6(+) } \\
\text { PTPRJ(+) } \\
\text { RAC2(+) } \\
\text { SMAD2(+) } \\
\text { TCF7L2(+) } \\
\text { VCL(+) }\end{array}$ & $\begin{array}{l}\text { INSR(+) } \\
\text { PTPRB5(-) } \\
\text { PTPN1 }(-)\end{array}$ & & $\begin{array}{l}\text { ACTN4(+) } \\
\text { CTNNA1(+) } \\
\text { GNA12(+) } \\
\text { HCLS1(+) } \\
\text { PRKCB1(+) } \\
\text { PRKCD(+) } \\
\text { PRKCG(+) } \\
\text { RAB13(+) } \\
\text { RRAS(+) } \\
\text { SPTAN1(+) }\end{array}$ & & \\
\hline
\end{tabular}

Table 2 The main KEGG metabolic pathways, regulatory pathways or molecular complexes that were found to be expressed in the myometrium on the basis of genes detected in genomic studies according to ${ }^{1} \mathrm{NP}-\mathrm{TNIL}$, to ${ }^{2} \mathrm{PTNIL}-\mathrm{TNIL}$ or to ${ }^{3} \mathrm{TNIL}-\mathrm{TIL}$, during the cycle or pregnancy. All gene transcripts showed at least a 2 fold or more, up (+) or down-regulation (-) after paired comparisons of the following stages: non-pregnant (NP) versus term not in labor (TNIL), preterm (PTNIL) versus TNIL, or TNIL versus term in labor (TIL). Brackets: number of genes represented in a defined pathway. A total of 118 genes were sorted as belonging to any of the 14 pathways, 0: no gene represented for the corresponding pathway. OMIM nomenclature adopted for genes names (see text).

Cytokine-cytokine receptors

Toll-like receptors

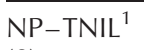

PTNIL-TNIL

(8)

$\operatorname{CCL} 19(+)$

CCL19(+)
CCL21 $(+)$

CCL21(+)

CSF1R $(+)$

$\operatorname{EGFR}(+)$

IL15RA(+)
IL6(+)

IL6ST(+)

TNFRSF11B(+)

(12)

TNIL-TIL ${ }^{3}$

NP-TNIL

(5)

PTNIL

BLR1(+)

CCL13(+)

CCL13(+)

CD14(+)

IKBKB $(-)$

$-\mathrm{TNIL}^{2}$

TNIL-TII

CXCR4(+)

CCL18(+)

$\mathrm{CD} 6(+)-\mathrm{KBKB}(-)$

IRAK1 $(-)$
MAP2K4(-)

L9(+)

CXCL10(+)

MAP2K4(-)

$\mathrm{CLC}(-)$

PIK3CB (-)

TNF $(-)$

EGF(-)

IFNGR1(-)

IL6ST(-)

LIFR (-)

$\operatorname{TNF}(-)$
$\operatorname{TNFSF} 4(-)$

\section{TFG-beta signaling pathway}

\begin{tabular}{lll}
\hline NP-TNIL & PTNIL-TNIL \\
& & TNIL-TIL \\
\end{tabular}

(6)

CXCL10(+)

ACVRL1 $(+) \quad$ THBS2 $(+)$

ROCK1 $(+)$

$\mathrm{NF}(-)$

THBS1 $(+)$

THBS2(t)

SMAD2(+)

THBS2(+)

THBS2 $(+$

Wnt signaling pathway

${\mathrm{NP}-\mathrm{TNIL}^{1}}^{1}$ PTNIL-TNIL ${ }^{2} \quad \mathrm{TNIL}^{-\mathrm{TIL}^{3}}$

(1)

$\mathrm{NLK}(+)$

MAPK10(-) VANGL1(+)

PRKCB1 $(+) \quad$ TP53(+)

PRKCG $(+)$

RAC2(+)

ROCK $1(+)$

SMAD2(+)

TCF7L2(+) 


\section{Parturition as an inflammatory process Cytokine-chemokines interaction}

There is a massive influx in the human myometrium of neutrophils, macrophages and T-lymphocytes concomitant with the onset of labor (Osman et al. 2003). An increase in cytokines, interleukin-1 (IL-1), IL-6, IL-8 and tumor necrosis factor (TNF)-alpha within tissues of the laboring uterus and cervix is demonstrated.

Chemokines enhance inflammation by inducing chemotaxis and cell activation of inflammatory cells. CXCchemokines, attract neutrophils but not macrophages, while CC-chemokines preferentially induce migration of macrophages. Chemokine transcripts increase in myometrium at term, including CCL13 (also known as monocyte chemotactic protein-4; MCP-4), CCL19, CCL21, CXCR4 (neuropeptide Y receptor-like; NPYRL) and CXCR5 (Burkitt lymphoma receptor) (Bethin et al. 2003, Charpigny et al. 2003, Rehman et al. 2003). At the time of labor, a selective increase in CXCL10 (Interferon-inducible protein-10), CCL8 and CCL13 is noted (Esplin et al. 2005; see Table 2). IL-8, MCP-1 and RANTES are regulated by local growth factors and cytokines such as TNF-alpha, interferon-gamma, and IL-1. IL-8 also potentiates the effect of IL-1-induced human myometrial contractions through prostaglandin $E_{2}$ $\left(\mathrm{PGE}_{2}\right)$ production at the time of parturition and up-regulates TGF-beta receptor expression in the human myometrium, suggesting an additional autocrine-signaling pathway. Therefore, it is clear that coordination of chemokine-chemokine receptor interactions plays an important role in successful pregnancy (Kayisli et al. 2002).

The TNF receptor super family member Fas and its cognate ligand (FasL) play a role in cell leiomyoma apoptosis (Wang et al. 2002). Therefore increased expression of TNF receptor S6 (TNFRS6; i.e. Fas receptor) in term myometrium (Table 2) await consideration in the control of the uterine growth process. Elevated expression of TNFRS11B is observed in human myometrium with or without labor (Esplin et al. 2005, Rehman et al. 2003). A peak in uterine osteoprotegerin (i.e. OPG or TNFRSF11B), a soluble membrane bound member of the TNF-alpha receptor family that acts as a negative regulator for receptor activator of nuclear factor-кB (RANK), has been reported during labor in the rat (Girotti \& Zingg 2003). It is of note that proinflammatory agents, like TNF-alpha, have been shown to repress G-alpha-s expression in human primary myometrial cells. This repression is mediated by the RelA nuclear factor $\kappa \mathrm{B}$ (NF-KB) subunit. However, RelA does not bind directly to the G-alpha-s promoter, suggesting repression is through a non-DNA-binding mechanism involving the coactivator, cAMP-response element binding protein-binding protein (CBP), implying that competition between individual promoters for this limiting cofactor may underpin the ability of RelA to down-regulate G-alpha-s immediately before parturition in humans (Chapman et al. 2005).

The gp130 protein is a subunit component of several cytokines receptors including those for leukemia inhibitory factor (LIF). Cytokines sharing the gp130 (or IL6ST) subunits are referred to as IL-6 type family of cytokines and signal through JAK/STAT pathway, reviewed in (Heinrich et al. 1998). They play a role in the regulation of gene activation, proliferation and differentiation. Down-regulation of IL6ST and LIF receptor at term (Table 3) may be an indication of the decrease of proliferation processes before the onset of labor.

Interferon-gamma (IFN-gamma) inhibits the proliferation of vascular smooth muscle cells and the synthesis of collagens by myofibroblasts. In human myometrial cells,

Table 3 The main KEGG metabolic pathways, regulatory pathways or molecular complexes that were found to be expressed in the myometrium on the basis of genes detected in genomic studies according to ${ }^{1}$ NP-TNIL, to ${ }^{2}$ PTNIL-TNIL or to ${ }^{3}$ TNIL-TIL, during the cycle or pregnancy. All gene transcripts showed at least a 2 fold or more, up (+) or down-regulation $(-)$ after paired comparisons of the following stages: non-pregnant (NP) versus term not in labor (TNIL), preterm (PTNIL) versus TNIL, or TNIL versus term in labor (TIL). Brackets: number of genes represented in a defined pathway. A total of 118 genes were sorted as belonging to any of the 14 pathways, 0 : no gene represented for the corresponding pathway. OMIM nomenclature adopted for gene names (see text).

MAPK signaling pathway

\begin{tabular}{|c|c|c|c|c|c|c|c|}
\hline NP-TNIL ${ }^{1}(15)$ & PTNIL-TNIL ${ }^{2}(12)$ & TNIL-TIL ${ }^{3}(4)$ & NP-TNIL ${ }^{1}(5)$ & PTNIL-TNIL ${ }^{2}(8)$ TNIL-TIL ${ }^{3}(0)$ & $\mathrm{NP}-\mathrm{TNIL}^{1}(6)$ & PTNIL-TNIL ${ }^{2}(7)$ & $\overline{T N I L-T^{3}(1)}$ \\
\hline $\begin{array}{l}\text { CD14(+) } \\
\text { EGFR(+) } \\
\text { FGFR1(+) } \\
\text { FLNA(+) } \\
\text { HSPA5(+) } \\
\text { HSPA8(+) } \\
\text { MAP3K5(+) } \\
\text { NLK(+) } \\
\text { PLA2G2A(+) } \\
\text { PRKCB1(+) } \\
\text { PRKCG(+) } \\
\text { RAC2(+) } \\
\text { RASGRP2(+) } \\
\text { RRAS(+) } \\
\text { YWHAZ(+) }\end{array}$ & $\begin{array}{l}\text { EGF(+) } \\
\text { IKBKB }(+) \\
\text { MAP2K4(+) } \\
\text { MAPK10(+) } \\
\text { PLA2G5(+) } \\
\text { RAP1A(+) } \\
\text { RASA1(+) } \\
\text { TNF(+) } \\
\text { TP53(+) } \\
\text { PLA2G2A(-) } \\
\text { PPP5C(-) } \\
\text { TNFRSF6(-) }\end{array}$ & $\begin{array}{l}\text { BDNF(+) } \\
\text { DUSP5(+) } \\
\text { NR4A1(+) } \\
\text { TGFB2(+) }\end{array}$ & $\begin{array}{l}\text { IMPA2 }(+) \\
\text { PIK3CA }(+) \\
\text { PIP5K1C }(+) \\
\text { PRKCB1 }(+) \\
\text { PRKCG }(+)\end{array}$ & $\begin{array}{l}\text { CALM1 }(-) \\
\text { CALM3(-) } \\
\text { DGKZ(-) } \\
\text { ITPR1(-) } \\
\text { ITPR1(-) } \\
\text { PIK3CB(-) } \\
\text { PLCG1(-) } \\
\text { PLCG2(-) }\end{array}$ & $\begin{array}{l}\text { IL15RA(+) } \\
\text { IL6(+) } \\
\text { IL6ST(+) } \\
\text { PIK3CA(+) } \\
\text { PTPN6(+) } \\
\text { STAT1(+) }\end{array}$ & $\begin{array}{l}\text { IL9(+) } \\
\text { PIM1(+) } \\
\text { CLC(-) } \\
\text { IFNGR1(-) } \\
\text { IL6ST(-) } \\
\text { LIFR(-) } \\
\text { PIK3CB (-) }\end{array}$ & IL13(+) \\
\hline
\end{tabular}


interferon gamma antagonizes IL-1beta-induced prostaglandin-endoperoxide synthase 2 (PGHS2, also more commonly known as COX-2 or PTGS2) expression and $\mathrm{PGE}_{2}$ production (Hertelendy et al. 2002). Therefore, the decrease in interferon gamma receptor 1 (IFNGR1) transcript observed during the transition from PTNIL to TNIL states of the uterus (Table 2), could be interpreted as an ad hoc evolution for labor onset.

\section{TLR signaling pathway}

Toll-like receptors (TLRs) are evolutionarily conserved pathogen-associated microbial patterns and play important roles in innate immunity in mammals. Ten TLRs are found in the non-pregnant human uterus but TLR2 and TLR4 mRNA are expressed in the highest levels (Nishimura \& Naito 2005). Among the TLR-related gene transcripts, supressor of cytokine signalling (SOCS), CD14 and interleukin-1 receptor-associated kinase 1 (IRAK) mRNAs (see Tables 2 and 4) are widely expressed in the myometrium. TLR4 mediates induction of pre-term labor (PTL) in mice treated with LPS (Wang \& Hirsch 2003). In human monocytes, LPS-induced signaling through TLRs, lead to the recruitment of docking proteins such as IRAK and TNF-alpha receptor-associated factor (TRAF6) leading to the activation of $І \kappa B$ kinase (IKK) complex. These pathways in turn activate transcription factor such as NF- $\mathrm{B}$ that coordinates the induction of genes encoding inflammatory mediators (reviewed in Guha \& Mackman 2001). In human pregnant myometrial cells a positive immunoreactivity for TLR4 is observed and cells exposure to LPS lead to nuclear translocation of the p65 subunit of NFkB (Dallot et al. 2005). The increased expression of CD14 together with increased expression of the catalytic subunit of phosphatidylinositol 3-kinase (PI3K) in pregnant myometrium may serve to increase host protection against microbial invasion (Rehman et al. 2003). At the end of pregnancy, because some of the TLR-related genes such as IRAK, IKK, MKK have decreased expression compared to earlier stage of the gestation (Charpigny et al. 2003), it is possible that adaptative responses to immune or growth processes take place.

\section{TGF-beta signaling pathway}

TGF-beta regulates its own expression, the expression of ECM, of matrix metalloproteinases (MMP), and of tissue inhibitor of matrix metalloproteinases (TIMP) as well as the growth of leiomyomas and of normal myometrial cells (Chegini et al. 1999). TGF-beta receptors mediate their action through multiple pathways, including SMAD proteins that convey TGF-beta receptor signals from the cell surface to the nucleus, resulting in transcriptional activation of TGF-beta responsive genes. TGF-beta also activates mitogen-activated protein kinase (MAPK), PKC, and calcium/calmodulin complex, inducing SMAD-independent transcriptional responses. One mechanism by which TGF-beta is activated involves thrombospondin (THBS1). THBS1 expression and protein in human myometrial tissues are increased during labor and after the administration of oxytocin (OT) (Morimoto et al. 1998). Myometrial transcripts of THBS1 and THBS2 increases during pregnancy (Charpigny et al. 2003, Rehman et al. 2003) and peak at the time of labor concomitantly with the expression of TGF-beta (Esplin et al. 2005). It is possible that the control of the TGF-beta pathway in the near term myometrium facilitates the transition of the quiescent uterus towards a contractile state, as well as a role in to control of uterine growth.

\section{Wnt signalling pathway}

Leiomyomas cells in culture have high levels of both transcripts of WNT5B and of secreted frizzled related protein 1 (SFRP1), a modulator of Wnt signaling (Mangioni et al. 2005). Strong SFRP1 expression under high estrogenic conditions seems to contribute to the development of human uterine leiomyomas through the antiapoptotic effect of SFRP1 (Fukuhara et al. 2002). The increased expression of WNT5B in the pregnant

Table 4 The main KEGG metabolic pathways, regulatory pathways or molecular complexes that were found to be expressed in the myometrium on the basis of genes detected in genomic studies according to ${ }^{1} \mathrm{NP}-\mathrm{TNIL}$, to ${ }^{2} \mathrm{PTNIL}-\mathrm{TNIL}$ or to ${ }^{3} \mathrm{TNIL}-\mathrm{TIL}$, during the cycle or pregnancy. All gene transcripts showed at least a 2 fold or more, up $(+)$ or down-regulation $(-)$ after paired comparisons of the following stages: non-pregnant (NP) versus term not in labor (TNIL), preterm (PTNIL) versus TNIL, or TNIL versus term in labor (TIL). Brackets: number of genes represented in a defined pathway. A total of 118 genes were sorted as belonging to any of the 14 pathways, 0 : no gene represented for the corresponding pathway. OMIM nomenclature adopted for gene names (see text).

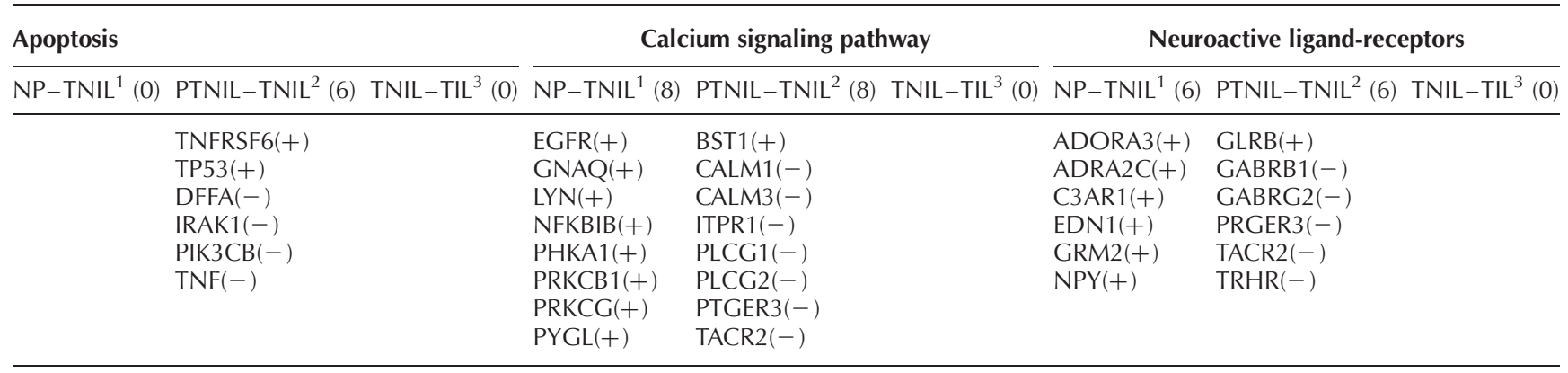



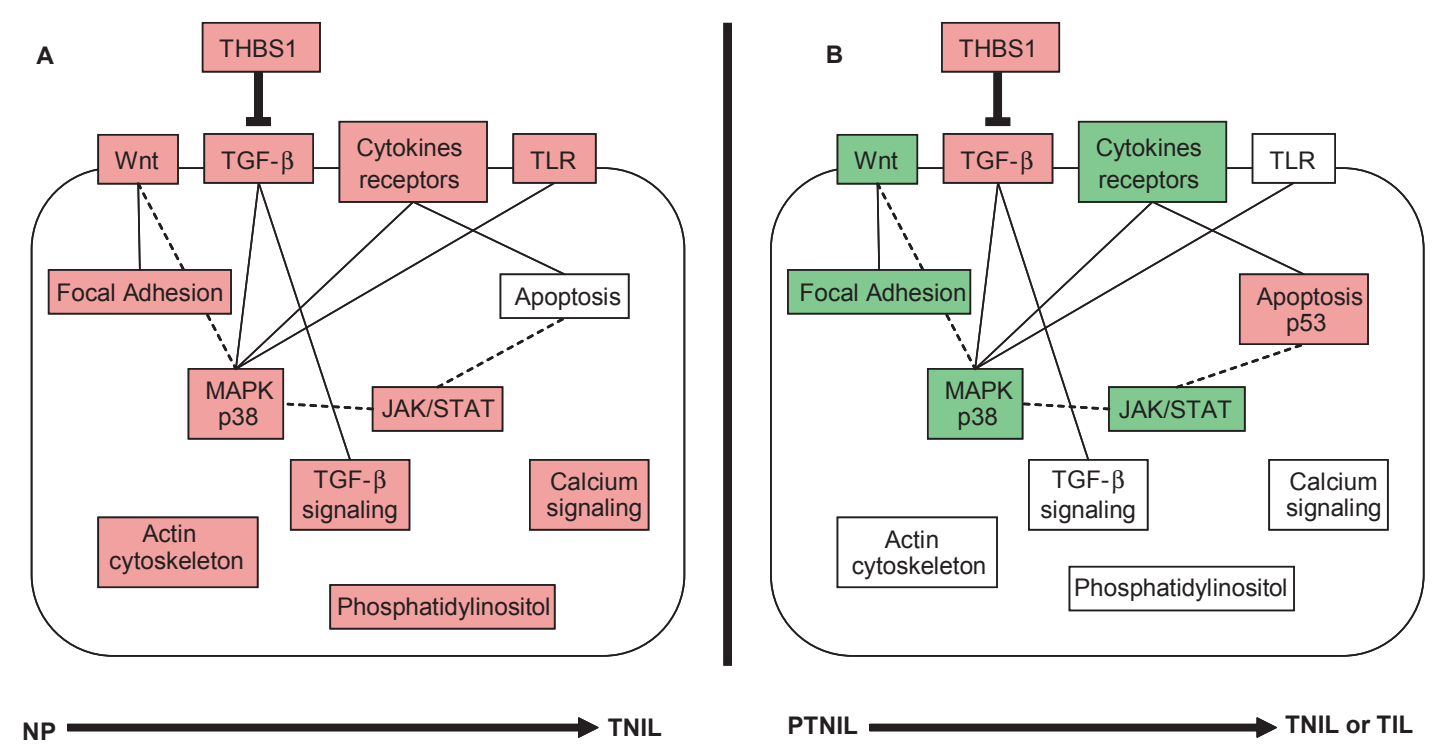

Figure 1 Main KEGG pathways represented in the myometrium on the basis of the genes detected in genomic studies. Gene transcripts pertaining to these pathways were either up-regulated (red) or down-regulated (green) by a two fold or more factor. White boxes denote insufficiently documented links in context. See Tables 1-4 for details. (A) Comparison between the non-pregnant (NP) and term not in labor (TNIL) uterus. (B) Comparison between the preterm not in labor (PTNIL) uterus and term in labor uterus (TNIL) or between TNIL and term in labor uterus (TIL). Five pathways (Focal adhesion, MAPK, TGF-beta, JAK/STAT and apoptosis) are shown with their known links to membrane receptors (Wnt, TGF-beta, cytokines and Toll-like receptors). Three additional pathways (actin cytoskeleton, phosphatidylinositol and calcium signaling are overexpressed in gestation by comparison to the non-pregnant state. THBS1; thrombospondin-1 (inhibitory).

myometrium suggests that the Wnt pathway is important in myometrial adaptation to pregnancy by decreasing apoptotic myometrial cell death (Rehman et al. 2003). Inversely, other genes associated with the inhibition of cell proliferation such as p53 are increased at the end of gestation (Charpigny et al. 2003).

\section{Kinases located at the crossroad of uterine contractility and myometrial cell proliferation MAPK-signaling pathway}

MAPK signaling cascades regulate diverse processes ranging from contraction, proliferation, differentiation, and development. Five families of MAPKs have been defined in mammalian cells: i) extracellular signal-regulated kinases (ERK1 and ERK2), ii) Jun $\mathrm{N}$-terminal kinases (JNK), iii) p38 kinase isozymes. ERK1 and ERK2 are activated by mitogenic stimuli such as growth factors, cytokines and phorbol esters. Members of the JNK family play crucial roles in regulating responses to various stresses and apoptosis. Among the targets of p38 MAPKs are several transcription factors, including NF- $\mathrm{KB}, \mathrm{p} 53$ and activating transcription factor 2 (ATF2), which modulate the expression of genes encoding inflammatory cytokines, see (Qi \& Elion 2005). MAPKs are involved in inhibiting gapjunction-mediated cellular communication in rat myometrium (Loch-Caruso et al. 2003). Mechanical stretch of the rat uterus stimulates myometrial cell hypertrophy (Douglas et al. 1988) via a mechanism involving integrin/focal adhesion/MAPK cascades (Macphee \& Lye 2000). Activation of MAPKs is necessary for optimal stretch-induced c-fos expression (Oldenhof et al. 2002). In addition, the spatial expression of MAPK p38 and ERK-1/2 in conjunction with ATF2 isoforms within the human uterine corpus during pregnancy and labor is likely to be important in preparation of the uterus for labor (Otun et al. 2005).

In human myometrial cells, the MAPK pathways are also implicated in the induction of COX-2 expression (PGHS2/PTGS2; Bartlett et al. 1999, Sooranna et al. 2004) and in mediating the effects of OT (Zhong et al. 2003) and corticotropin-releasing hormone (CRH) (Grammatopoulos et al. 2000, Papadopoulou et al. 2004). Increasing maternal plasma levels of $\mathrm{CRH}$ during the last weeks of pregnancy and the substantial expression of CRH receptors in choriodecidua, placenta and myometrium suggests that this stress hormone plays a role in the control of human parturition (Sehringer et al. 2004). Moreover, MAPK cascade is involved in PGF $_{2 \alpha}$ (Ohmichi et al. 1997) and endothelin-1 (ET-1) (Kimura et al. 1999) induced rat puerperal contraction. The MAPK activity increases in the rat myometrium from day 15 to day 20 of gestation and declines sharply just before parturition (Robin et al. 2004). During the same interval, a shift in intracellular distribution of the Ras protein precedes the down-regulation of membrane-dependent mitogenic signaling and uterine hypertrophy as gestation approaches parturition (Ruzycky 1998). In a rat model of preterm labor, ERK 


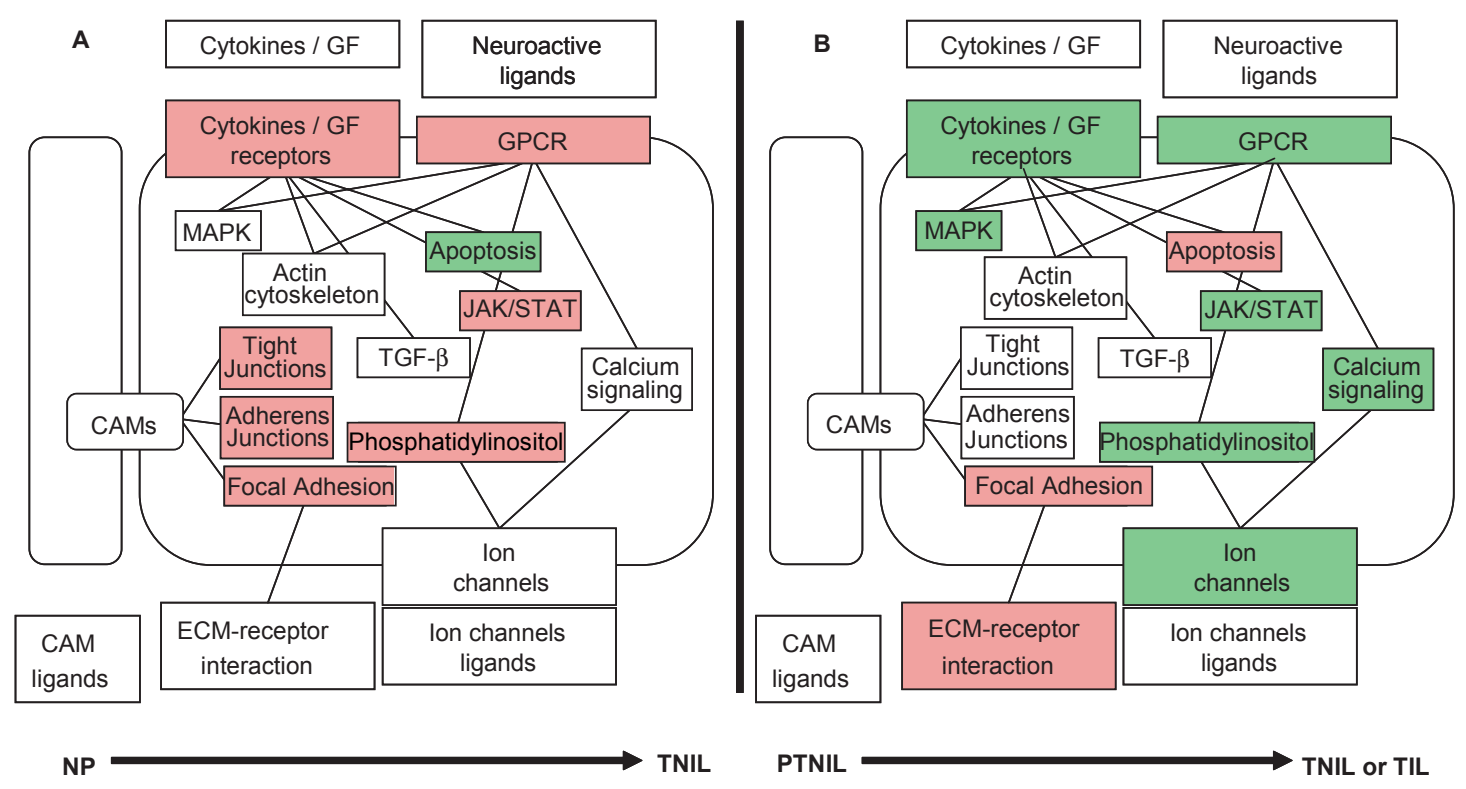

Figure 2 Main KEGG pathways represented in the myometrium on the basis of the genes detected in genomic studies. Gene transcripts pertaining to these pathways were either up-regulated (red) or down-regulated (green) by a two fold or more factor. White boxes denote insufficiently documented links in context. See Tables 1-4 for details. (A) Comparison between the non-pregnant (NP) and term not in labour (TNIL) uterus. (B) Comparison between the preterm not in labor (PTNIL) uterus and term in labor uterus (TNIL) or between TNIL and term in labor uterus (TIL). Ten pathways (focal adhesion, adherens junctions, tight junctions, actin cytoskeleton, phosphatidylinositol and calcium signaling, MAPK, TGFbeta, JAK/STAT and apoptosis) are shown with their known links to cytokine, growth factors (GF) and G-protein coupled membrane receptors. CAMs; cell adhesion molecules. ECM; extra-cellular matrix.

phosphorylation levels increase, as does phosphorylation of caldesmon and of a 20-kDa myosin light chain subunit (MLC). When rats are chronically treated with an agent that prevents ERK activation, the onset of PTL is delayed (Li et al. 2004, Liu et al. 2004).

OT-mediated ERK1/2 activation in human myometrial cells involves a phospholipase C (PLC)-independent pathway (Zhong et al. 2003). Cross-talk between growth factor receptors and the estrogen receptor alpha (ESR1) has been proposed. The estrogen response involves estradiol (E2)-ESR1-mediated responses as well as responses resulting from convergence of growth factor and ESR1-initiated activities in the mouse uterus (Hewitt et al. 2005). Functional signaling proximal to IGF-IR is maintained in the ER alpha knock-out mouse uterus. ER alpha is necessary for IGF-I induction of uterine nuclear proliferative responses, and a cross-talk between IGF-IR and ER signaling pathways exists in vivo (Klotz et al. 2002).

\section{Protein kinase $C$}

PKC constitute a multigene family located at the crossroad of two essential uterine functions, namely contractility and cell proliferation. Six isoforms of PKC, the conventional PKC isoforms (alpha, betal, betall, and gamma), the novel PKC isoforms (delta, epsilon, theta, eta, lambda/iota) and the atypical PKC isoform (zeta) are evidenced in the human pregnant myometrium. Whereas protein kinase $\mathrm{C}$ alpha (PRKCA) is required for proliferation of human myometrial cells (Eude et al. 2002), only activation of PRKCZ results in actin reorganization and elicits contractions of the human myometrium at the end of pregnancy (Di Liberto et al. 2003).

A balance between $\mathrm{T}$ helper (Th1) (pro-inflammatory) and Th2 (anti-inflammatory) cytokine production, has been described at the time of parturition, a link between TNF-alpha and IL1-beta in premature human childbirth has been proposed (Arntzen et al. 1998). Because, atypical PKCs are important components of the TNF/interleukin 1-beta (IL1B) signaling pathway that controls NF- $\mathrm{kB}$ activation, the implication of the PRKCZ in the control of the onset of labor in women is not surprising. (Ozaki et al. 2003) also demonstrated that the levels of mRNA of PRKCB1 isoform in pregnant human myometrium were greater than those in nonpregnant myometrium, a feature confirmed in genomic studies (Table 3) (Rehman et al. 2003). The levels of the phosphorylated substrate for PKC, protein kinase C-potentiated inhibitor of protein phosphatase $17-\mathrm{kDa}$ (CPI-17) which is considered to inhibit myosin light chain phosphatase was also greater in the pregnant myometrium. These results suggest that the PKC-mediated contractile mechanism is augmented in human myometrium after gestation, and that this augmentation may be attributable to the increased activity of the PRKCB1 isoform and CPI-17. 


\section{Phosphatidyl inositol signaling pathway}

The PI3K cascade is activated through the binding of the regulatory subunit to phosphorylated tyrosine residues, leading to enhanced activity of the catalytic subunit. PI3K phosphorylates phosphatidyliositol-4,5-bisphosphate (PIP2) to generate PIP3 which interacts with protein kinase Akt or protein kinase B (PKB). Activation of Akt influences many cellular functions through PIP3 binding and phosphorylation by phosphoinositide-dependent kinase 1 (PDK1). It includes cytoskeletal organization, cell growth, motility, proliferation and survival. PDK1 is known to phosphorylate PKC-zeta in the activation loop. PI3K is also activated by direct binding of the catalytic subunit to activated Ras and PI3K cascade activation can lead to the activation of the ERK cascade (reviewed in Stein \& Waterfield 2000).

Increases in $\left[\mathrm{Ca}^{2+}\right]_{i}$ are controlled by multiple signal pathways in myometrium. G protein coupled receptor (GCPR)-mediated stimulation of the $\mathrm{Gq} / 11$ subfamily and subsequent activation of PLC subfamily results in generation of IP3, which triggers release of $\mathrm{Ca}^{2+}$ from the sarcoplasmic reticulum.

Five PLC isoforms: beta 1, beta 2, beta 3, gamma 1, and gamma 2 (PLCB1-4, PLCG1-2) are detected in human myometrium. OT activates human myometrium by interacting with at least two G proteins and possibly three PLC beta isoforms (Phaneuf et al. 1996). Indeed, the amount of PLCB4 is increased at midpregnancy, whereas PLCB1, PLCB2, and PLCB3 are up-regulated at term in the rat uterus (Mhaouty-Kodja et al. 2004). PLCB3 may be targeted by both contractant and relaxant signaling pathways in the human myometrium and play a critical role in the balance between them (Zhong et al. 2005). Both DAG-sensitive PKC, activated by PLCB products, and diacylglycerol (DAG)-insensitive PKC, possibly activated by PI3K-dependent process are involved in ERK activation to modulate rat uterine functions (Robin et al. 2002). In addition, protein tyrosine kinase/phosphatase activities may control both phosphorylation and activation of PLCG1 and contribute to the modulation of the generation of inositol phosphates and uterine tension.

Genomic studies exploring the transition from the NP to the TNIL state found an up-regulation of the transcripts pertaining to the phosphoinositol signaling pathway (Rehman et al. 2003), whereas those comparing the PTNIL to the TNIL state found a down-regulation of transcript expression (Bethin et al. 2003, Charpigny et al. 2003). This may be interpreted as a slowdown of myometrial cell proliferation processes when pregnancy comes close to term (Table 3).

\section{Apoptosis and parturition}

Proliferation of smooth muscle cells and fibroblasts occurs in early pregnancy and decreases as the uterus nears par- turition. In late pregnancy and during involution of the rat uterus, an increase of apoptosis is observed (Leppert 1998). More recently, (Shynlova et al. 2006) proposed two distinct phases of myometrial growth in the rat: a myocyte hyperplasia associated with increase in anti-apoptotic proteins in the first half of gestation and a cellular hypertrophy in the second part; the transition period is characterized by caspase cascade activation for triggering the differentiation of the uterine smooth muscle. However, the extent of apoptosis or dedifferentiation that may occur in human myometrial cells during post-partum involution is still unknown. The most investigated factors linked to apoptosis are the Fas ligand (FasL), Fas receptor (FasR), the TNF-alpha and its receptors. Some of the genes associated with the inhibition of cell proliferation and differentiation are increased in the myometrium at the end of pregnancy (Table 4). For an example, the TNFR6 or Fas antigen and the p53 tumor suppressor limit cellular proliferation by inducing cell cycle arrest and apoptosis. The presence of DFFA (DNA fragmentation factor-45), known to be essential for chromatin condensation during normal apoptosis and the inhibition of the PI3K in the term pregnant myometrium, may also contribute to an increase of apoptotic events.

\section{G-protein signaling and parturition}

The silencing of the myometrial contractile function is conditioned by a predominant functional cAMP/cGMP system, whereas contractions are under the control of agonist-induced calcium mobilization via the PLC pathway. Gestational-related modifications of GPCR in the human myometrium, as well as changes in their associated kinases (GRK), cognate G proteins, and effectors have been detected (Lopez Bernal \& TambyRaja 2000, Hertelendy \& Zakar 2004). Some GPCRs coupled to PLC generate the second messengers IP3 and DAG. The ensuing rise in IP3 releases $\mathrm{Ca}^{2+}$ from the sarcoplasmic reticulum, causing a sudden rise in intracellular calcium, whereas DAG activates PKC and the MAPK cascades. Uterine contractility can also be enhanced via the activation of Rho GTPases, and the subsequent action of ROCKs to potentiate the effect of myosin light chain kinase (MLCK, also known as MYLK). These pathways have been discussed above. Other GPCRs coupled to the adenylyl cyclase promotes the accumulation of cAMP which controls the relaxation of the myometrium during pregnancy via the inactivation of MLCK and the activation of ATF2, a DNA-binding protein that binds to CAMP response elements (CREs) and stimulates CREdependent transcription (Bailey \& Europe-Finner 2005). Another powerful way for increasing cAMP concentration consists of inhibiting its hydrolysis by phosphodiesterases (PDEs). Among the five PDE families (PDE 1, 2, 3, 4 and 5) identified in the human myometrium (Leroy et al. 1994, Leroy et al. 1999), one particular isoform, 
PDE4B2, which specifically hydrolyses cAMP is selectively induced at the end of pregnancy suggesting a role for this protein in the setting of the contractile state of the myometrium just before delivery (Mehats et al. 2000, Mehats et al. 2001).

\section{Neuroactive-ligands and parturition}

A small selection of peptides, neuroactive factors and ion channels such as ET-1, noradrenaline, neuropeptide $Y$ (NPY), $\mathrm{PGE}_{2}$ and gamma-aminobutyric acid (GABA) that mediate uterine relaxation or contraction and act through GPCRs are mentioned here (see Table 4). ET-1 was first described as a potent modulator of uterine contractions for a review see Hertelendy \& Zakar (2004) - but also has mitogenic properties in humans (Breuiller-Fouche et al. 1998) and rat myometrial cells (Robin et al. 2002). ET-1 transcript is up-regulated in the pregnant myometrium (Rehman et al. 2003). Among the three subtypes of alpha2-adrenoceptors found in the human myometrium at term pregnancy (Adolfsson et al. 1998), only the alpha2Csubtype appears to be predominant in pregnant myometrium. Stimulation of GABA (A) receptors tonically inhibits contractions of the rabbit myometrium, while stimulation of GABA (B) receptors enhances contractions. Steroids interact with $\mathrm{GABA}(\mathrm{A})$ receptors to modulate uterine contractility (Majewska \& Vaupel 1991). The subunit composition of GABA (A) receptor differs in rat uteri throughout gestation and just before labor in humans, a decline in GABA receptor transcripts is observed as shown in Table 4 (Bethin et al. 2003, Charpigny et al. 2003). Thyrotropinreleasing hormone-receptor (TRH-R) is expressed in term myometrium. (Fukusumi et al. 1995) have previously reported high level of TRH-R mRNA in the rat uterus but whether TRH plays an important role in the female reproductive tract remains to be elucidated. Prostaglandins, in conjunction with their numerous receptors activate multiple signaling pathways and exert multifaceted actions in myometrium (Hertelendy \& Zakar 2004). Thus, EP3 transcripts are down-regulated in the term pregnant myometrium (Bethin et al. 2003, Charpigny et al. 2003). However, the significance of these changes remains to be established, because of the known existence of EP3 splice variants.

\section{Future strategies for integrative analysis of myometrial functions}

A question is what could be the composition of an 'ideal' genomic array for the study of parturition? The answer is not unique. 'Generic' microarrays (i.e. having the broadest representation of transcripts) seem heuristically more potent to explore and detect new interesting metabolic pathways than arrays dedicated to a specific cell type (Tierney et al. 2003) because parturition involves interactions of many categories of cells, even within a rather simple tissue like the myometrium. Only in a second step, specialized arrays can be useful to investigate the physiological regulations of a precise cell population following its individualization within a given tissue. Typically, tissue and cell tests are additional.

Gene module analysis, as exemplified in this review, searches for coordinate regulation of genes that belong to a priori defined gene modules. A statistical test performed for each module relative to all other genes on the microarray calculates whether the degree of coordinate regulation is more than one would expect by chance. Therefore, a module of genes involved in a physiological process may be significantly down-regulated whereas each gene in the module under study may be transcriptionally down regulated by say only $20 \%$, and thus not clearly detected at the individual gene level (Tierney et al. 2003, Wong \& Chang 2005). In addition, beside classical ideas regarding trans-regulation of gene expression, a greater number of hypotheses generated from regulatory networks analysis or cis-regulatory DNA elements analysis can be validated today in a high throughput fashion using chromatin-immunoprecipitation followed by microarray analysis (ChIPchip). For example, a large fraction of genes transcribed in the liver and pancreas have been found to bind HNF4, providing a molecular explanation for the role of HNF4 mutations and polymorphisms in hereditary and sporadic forms of diabetes mellitus (Odom et al. 2004).

In the majority, transcripts are not tissue-restricted, but are present to varying degrees in a wide variety of cell types - although there are exceptions, like myosin heavy chain which is primarily found in smooth muscle cells. As such, it is not necessary to create arrays only from cDNAs obtained from dedicated libraries. Many sources of clones can be used for array analyses including microarrays purchased from companies (e.g. Incyte, Affymetrix, Clontech), which consist of cDNA clones or oligonucleotides that cover a large percentage of the transcripts (known as ESTs) present in public databases (Juhasz et al. 2002). Only in the context of a well defined cell population, can DNA microarray data be used in a comprehensive analysis aimed at identifying the shared and unique molecular 'modules' underlying a pathological process. Thus, in peripheral organs, laser microdissection of their constitutive compartments may reveal distinct repertoires of apoptosisassociated genes, chemokines and chemokine receptors in these compartments (Shen et al. 2004).

Microarray technology has made it possible to widen our comprehension of the major structural and metabolic transformations which affect the myometrium from the very beginning of pregnancy until parturition. The results have proven to be coherent with the mass of information which was accumulated previously, primarily on the basis of the study of selected critical factors. Although still limited in number, the recent studies highlight the activation of precise signaling pathways, some of which may have been under evaluated. Thus, the remodelling and maturation processes that the uterus undergoes in pregnancy 
appear clearly as phenomena which last during the full course of gestation. This is attested by the nature of the main signaling pathways represented, in comparison with the non pregnant-uterus versus term uterus and the comparison of the preterm uterus versus the term uterus in labor. Comparatively, the onset of labor is perhaps the phenomenon which remains the least well described by these methods of analysis, possibly because it is a phenomenon occurring in too short window to have been grasped by the few studies carried out up to now. Whatever it may be, genomic studies constitute a necessary first step of orientation which should lead to a more elaborate hierarchical vision of the physiological mechanisms of gestation, in particular by establishing new links between the generic signaling pathways that are activated during normal or pathological gestation. Genomic studies also represent an indicative step that will need to be correlated with a systematic proteomic analysis of the myometrium (Riley et al. 2005a, Riley et al. 2005b). The latter will undoubtedly develop in the very near future.

Building comprehensive strategies of genomic and proteomic analysis to explore physiologic functions remains today a challenge to which very few research groups have devoted their energy, and so far only for biological functions unrelated to the pregnant uterus (Ho et al. 2003). It is our hope that the merit of the studies analyzed in this review will provide enough confidence to apply this technology to far wider sample populations and enable subcategorizations on the basis of gestational length, multiple pregnancy, ethnicity and disease. This will be hardly possible without the implementation of a genuine cooperation at a larger scale amongst many research groupings.

\section{Acknowledgements}

We thank the reviewers for their thorough and insightful comments. The authors declare that there is no conflict of interest that would prejudice the impartiality of this scientific work.

\section{References}

Adolfsson PI, Dahle LO, Berg G \& Svensson SP 1998 Characterization of alpha2-adrenoceptor subtypes in pregnant human myometrium. Gynecologic and Obstetric Investigation 45 145-150.

Aguan K, Carvajal JA, Thompson LP \& Weiner CP 2000 Application of a functional genomics approach to identify differentially expressed genes in human myometrium during pregnancy and labour. Molecular Human Reproduction 6 1141-1145.

Allison DB, Cui X, Page GP \& Sabripour M 2006 Microarray data analysis: from disarray to consolidation and consensus. Nature Reviews Genetics 7 55-65.

Arntzen KJ, Kjollesdal AM, Halgunset J, Vatten L \& Austgulen R 1998 TNF, IL-1, IL-6, IL-8 and soluble TNF receptors in relation to chorioamnionitis and premature labor. Journal of Perinatal Medicine 26 17-26.

Bailey J \& Europe-Finner GN 2005 Identification of human myometrial target genes of the c-Jun $\mathrm{NH} 2$-terminal kinase (JNK) pathway: the role of activating transcription factor 2 (ATF2) and a novel spliced isoform ATF2-small. Journal of Molecular Endocrinology 34 19-35.

Bailey J, Tyson-Capper AJ, Gilmore K, Robson SC \& Europe-Finner GN 2005 Identification of human myometrial target genes of the CAMP pathway: the role of cAMP-response element binding (CREB) and modulator (CREMalpha and CREMtau2alpha) proteins. Journal of Molecular Endocrinology 34 1-17.

Bartlett SR, Sawdy R \& Mann GE 1999 Induction of cyclooxygenase2 expression in human myometrial smooth muscle cells by interleukin-1beta: involvement of p38 mitogen-activated protein kinase. Journal of Physiology 520 399-406.

Bethin KE, Nagai Y, Sladek R, Asada M, Sadovsky Y, Hudson TJ \& Muglia LJ 2003 Microarray analysis of uterine gene expression in mouse and human pregnancy. Molecular Endocrinology 17 1454-1469.

Breuiller-Fouche M, Heluy V, Fournier T, Dallot E, Vacher-Lavenu MC \& Ferre F 1998 Role of endothelin-1 in regulating proliferation of cultured human uterine smooth muscle cells. Molecular Human Reproduction 4 33-39.

Chan EC, Fraser S, Yin S, Yeo G, Kwek K, Fairclough RJ \& Smith R 2002 Human myometrial genes are differentially expressed in labor: a suppression subtractive hybridization study. Journal of Clinical Endocrinology and Metabolism 87 2435-2441.

Chapman NR, Smyrnias I, Anumba DO, Europe-Finner GN \& Robson SC 2005 Expression of the GTP-binding protein (Galphas) is repressed by the nuclear factor kappaB RelA subunit in human myometrium. Endocrinology 146 4994-5002.

Charpigny G, Leroy MJ, Breuiller-Fouche M, Tanfin Z, MhaoutyKodja S, Robin P, Leiber D, Cohen-Tannoudji J, Cabrol D, Barberis C et al. 2003 A functional genomic study to identify differential gene expression in the preterm and term human myometrium. Biology of Reproduction 68 2289-2296.

Chegini N, Tang XM \& Ma C 1999 Regulation of transforming growth factor-beta1 expression by granulocyte macrophage-colony-stimulating factor in leiomyoma and myometrial smooth muscle cells. Journal of Clinical Endocrinology and Metabolism 84 4138-4143.

Chen HW, Chen JJ, Tzeng CR, Li HN, Chang SJ, Cheng YF, Chang CW, Wang RS, Yang PC \& Lee YT 2002 Global analysis of differentially expressed genes in early gestational decidua and chorionic villi using a 9600 human cDNA microarray. Molecular Human Reproduction 8 475-484.

Claverie JM 1999 Computational methods for the identification of differential and coordinated gene expression. Human Molecular Genetics 8 1821-1832.

Dallot E, Mehats C, Oger S, Leroy MJ \& Breuiller-Fouche M 2005 A role for PKCzeta in the LPS-induced translocation NF-kappaB p65 subunit in cultured myometrial cells. Biochimie 87 513-521.

Di Liberto G, Dallot E, Eude-Le Parco I, Cabrol D, Ferre F \& Breuiller-Fouche M 2003 A critical role for PKC zeta in endothelin-1-induced uterine contractions at the end of pregnancy. American Journal of Physiology, Cell Physiology 285 C599-C607.

Douglas AJ, Clarke EW \& Goldspink DF 1988 Influence of mechanical stretch on growth and protein turnover of rat uterus. American Journal of Physiology 254 E543-E548.

Draghici S, Khatri P, Martins RP, Ostermeier GC \& Krawetz SA 2003 Global functional profiling of gene expression. Genomics 81 98-104.

Dunckley T, Coon KD \& Stephan DA 2005 Discovery and development of biomarkers of neurological disease. Drug Discovery Today $10326-334$.

Esplin MS, Fausett MB, Peltier MR, Hamblin S, Silver RM, Branch DW, Adashi EY \& Whiting D 2005 The use of cDNA microarray to identify differentially expressed labor-associated genes within the human myometrium during labor. American Journal of Obstetrics and Gynecology 193 404-413.

Eude I, Dallot E, Ferre F \& Breuiller-Fouche M 2002 Protein kinase Calpha is required for endothelin-1-induced proliferation of human myometrial cells. Biology of Reproduction 66 44-49. 
Fukuhara K, Kariya M, Kita M, Shime H, Kanamori T, Kosaka C, Orii A, Fujita J \& Fujii S 2002 Secreted frizzled related protein 1 is overexpressed in uterine leiomyomas, associated with a high estrogenic environment and unrelated to proliferative activity. Journal of Clinical Endocrinology and Metabolism 87 1729-1736.

Fukusumi S, Ogi K, Onda H \& Hinuma S 1995 Distribution of thyrotropin-releasing hormone receptor mRNA in rat peripheral tissues. Regulatory Peptides 57 115-121.

Ganesh SK, Skelding KA, Mehta L, O'Neill K, Joo J, Zheng G, Goldstein J, Simari R, Billings E, Geller NL et al. 2004 Rationale and study design of the CardioGene Study: genomics of in-stent restenosis. Pharmacogenomics 5 952-1004.

Gargiulo AR, Khan-Dawood FS \& Dawood MY 1997 Epidermal growth factor receptors in uteroplacental tissues in term pregnancy before and after the onset of labor. Journal of Clinical Endocrinology and Metabolism 82 113-117.

Girotti M \& Zingg HH 2003 Gene expression profiling of rat uterus at different stages of parturition. Endocrinology 144 2254-2265.

Gogarten W, Emala CW, Lindeman KS \& Hirshman CA 2001 Oxytocin and lysophosphatidic acid induce stress fiber formation in human myometrial cells via a pathway involving Rho-kinase. Biology of Reproduction 65 401-406.

Grammatopoulos DK, Randeva HS, Levine MA, Katsanou ES \& Hillhouse EW 2000 Urocortin, but not corticotropin-releasing hormone $(\mathrm{CRH})$, activates the mitogen-activated protein kinase signal transduction pathway in human pregnant myometrium: an effect mediated via R1alpha and R2beta CRH receptor subtypes and stimulation of Gq-proteins. Molecular Endocrinology $\mathbf{1 4}$ 2076-2091.

Guha M \& Mackman N 2001 LPS induction of gene expression in human monocytes. Cellular Signalling 13 85-94.

Havelock JC, Keller P, Muleba N, Mayhew BA, Casey BM, Rainey WE \& Word RA 2005 Human myometrial gene expression before and during parturition. Biology of Reproduction 72 707-719.

Heinrich PC, Behrmann I, Muller-Newen G, Schaper F \& Graeve L 1998 Interleukin-6-type cytokine signalling through the gp130/Jak/STAT pathway. Biochemical Journal 334 297-314.

Hertelendy F \& Zakar T 2004 Regulation of myometrial smooth muscle functions. Current Pharmaceutical Design 10 2499-2517.

Hertelendy F, Molnar M \& Romero R 2002 Interferon gamma antagonizes interleukin-1beta-induced cyclooxygenase- 2 expression and prostaglandin $\mathrm{E}(2)$ production in human myometrial cells. Journal of the Society for Gynecological Investigation 9 215-219.

Hewitt SC, Collins J, Grissom S, Deroo B \& Korach KS 2005 Global uterine genomics in vivo: microarray evaluation of the estrogen receptor alpha-growth factor cross-talk mechanism. Molecular Endocrinology 19 657-668.

Ho $M$, Yang E, Matcuk G, Deng D, Sampas N, Tsalenko A, Tabibiazar R, Zhang Y, Chen M, Talbi S et al. 2003 Identification of endothelial cell genes by combined database mining and microarray analysis. Physiological Genomics 13 249-262.

Juhasz O, Zhu Y, Garg R, Anisimov SV \& Boheler KR 2002 Analysis of altered genomic expression profiles in the senescent and diseased myocardium using cDNA microarrays. European Journal of Heart Failure 4 687-697.

Kanehisa M 1997 A database for post-genome analysis. Trends in Genetics 13 375-376.

Kanehisa M \& Goto S 2000 KEGG: kyoto encyclopedia of genes and genomes. Nucleic Acids Research 28 27-30.

Kato HD, Terao Y, Ogawa M, Matsuda T, Arima T, Kato K, Yong Z \& Wake N 2002 Growth-associated gene expression profiles by microarray analysis of trophoblast of molar pregnancies and normal villi. International Jounal of Gynecological Pathology $21255-260$.

Kayisli UA, Mahutte NG \& Arici A 2002 Uterine chemokines in reproductive physiology and pathology. American Journal of Reproductive Immunology 47 213-221.
Keelan JA, Blumenstein M, Helliwell RJ, Sato TA, Marvin KW \& Mitchell MD 2003 Cytokines, prostaglandins and parturition-a review. Placenta 24 (Supplement A) S33-S46.

Khatri P \& Draghici S 2005 Ontological analysis of gene expression data: current tools, limitations, and open problems. Bioinformatics 21 3587-3595.

Khatri P, Sellamuthu S, Malhotra P, Amin K, Done A \& Draghici S 2005 Recent additions and improvements to the Onto-Tools. Nucleic Acids Research 33 W762-W765.

Kimura A, Ohmichi M, Takeda T, Kurachi H, Ikegami H, Koike K, Masuhara K, Hayakawa J, Kanzaki T, Kobayashi M et al. 1999 Mitogen-activated protein kinase cascade is involved in endothelin-1-induced rat puerperal uterine contraction. Endocrinology 140 $722-731$.

Klotz DM, Hewitt SC, Ciana P, Raviscioni M, Lindzey JK, Foley J, Maggi A, DiAugustine RP \& Korach KS 2002 Requirement of estrogen receptor-alpha in insulin-like growth factor-1 (IGF-I)-induced uterine responses and in vivo evidence for IGF-l/estrogen receptor cross-talk. Journal of Biological Chemistry 277 8531-8537.

Leppert PC 1998 Proliferation and apoptosis of fibroblasts and smooth muscle cells in rat uterine cervix throughout gestation and the effect of the antiprogesterone onapristone. American Journal of Obstetrics and Gynecology 178 713-725.

Leroy MJ, Lugnier C, Merezak J, Tanguy G, Olivier S, Le Bec A \& Ferre F 1994 Isolation and characterization of the rolipram-sensitive cyclic AMP-specific phosphodiesterase (type IV PDE) in human term myometrium. Cellular Signalling 6 405-412.

Leroy MJ, Mehats C, Duc-Goiran P, Tanguy G, Robert B, Dallot E, Mignot TM, Grange G \& Ferre F 1999 Effect of pregnancy on PDE4 cAMP-specific phosphodiesterase messenger ribonucleic acid expression in human myometrium. Cellular Signalling 11 31-37.

Lewis SE 2005 Gene Ontology: looking backwards and forwards. Genome Biology 6103.

Li Y, Je HD, Malek S \& Morgan KG 2004 Role of ERK1/2 in uterine contractility and preterm labor in rats. American Journal of Physiology, Regulative, Integrative and Comparative Physiology 287 R328-R335.

Liu Y, Dong W, Chen L, Xiang R, Xiao H, De G, Wang Z \& Qi Y 2004 BCL10 mediates lipopolysaccharide/toll-like receptor-4 signaling through interaction with Pellino2. Journal of Biological Chemistry 279 37436-37444.

Loch-Caruso RK, Criswell KA, Grindatti CM \& Brant KA 2003 Sustained inhibition of rat myometrial gap junctions and contractions by lindane. Reproductive Biology and Endocrinology 162.

Lopez Bernal A \& TambyRaja RL 2000 Preterm labour. Baillieres Best Practice \& Research, Clinical Obstetrics and Gynaecology 14 $133-153$.

Macphee DJ \& Lye SJ 2000 Focal adhesion signaling in the rat myometrium is abruptly terminated with the onset of labor. Endocrinology $141274-283$.

Majewska MD \& Vaupel DB 1991 Steroid control of uterine motility via gamma-aminobutyric acidA receptors in the rabbit: a novel mechanism? Journal of Endocrinology 131 427-434.

Mangioni S, Vigano P, Lattuada D, Abbiati A, Vignali M \& Di Blasio AM 2005 Overexpression of the Wnt5b gene in leiomyoma cells: implications for a role of the Wnt signaling pathway in the uterine benign tumor. Journal of Clinical Endocrinology and Metabolism $905349-5355$.

Marvin KW, Keelan JA, Eykholt RL, Sato TA \& Mitchell MD 2002a Use of cDNA arrays to generate differential expression profiles for inflammatory genes in human gestational membranes delivered at term and preterm. Molecular Human Reproduction 8 399-408.

Marvin KW, Keelan JA, Eykholt RL, Sato TA \& Mitchell MD 2002b Expression of angiogenic and neurotrophic factors in the human amnion and choriodecidua. American Journal of Obstetrics and Gynecology 187 728-734.

Mehats C, Tanguy G, Dallot E, Cabrol D, Ferre F \& Leroy MJ 2001 Is up-regulation of phosphodiesterase 4 activity by PGE2 involved in the desensitization of beta-mimetics in late pregnancy human 
myometrium? Journal of Clinical Endocrinology and Metabolism 86 5358-5365.

Mehats C, Tanguy G, Paris B, Robert B, Pernin N, Ferre F \& Leroy MJ 2000 Pregnancy induces a modulation of the cAMP phosphodiesterase 4-conformers ratio in human myometrium: consequences for the utero-relaxant effect of PDE4-selective inhibitors. Journal of Pharmacology and Experimental Therapeutics $292817-823$.

Mhaouty-Kodja S, Houdeau E \& Legrand C 2004 Regulation of myometrial phospholipase $\mathrm{C}$ system and uterine contraction by betaadrenergic receptors in midpregnant rat. Biology of Reproduction 70 570-576

Moore F, Da Silva C, Wilde JI, Smarason A, Watson SP \& Lopez Bernal A 2000 Up-regulation of p21- and RhoA-activated protein kinases in human pregnant myometrium. Biochemical and Biophysical Research Communications $269322-326$.

Morimoto T, Head JR, MacDonald PC \& Casey ML 1998 Thrombospondin-1 expression in human myometrium before and during pregnancy, before and during labor, and in human myometrial cells in culture. Biology of Reproduction 59 862-870.

Muhle RA, Pavlidis P, Grundy WN \& Hirsch E 2001 A high-throughput study of gene expression in preterm labor with a subtractive microarray approach. American Journal of Obstetrics and Gynecology $185716-724$.

Nishimura M \& Naito S 2005 Tissue-specific mRNA expression profiles of human toll-like receptors and related genes. Biological \& Pharmiceutical Bulletin 28 886-892.

Odom DT, Zizlsperger N, Gordon DB, Bell GW, Rinaldi NJ, Murray HL, Volkert TL, Schreiber J, Rolfe PA, Gifford DK et al. 2004 Control of pancreas and liver gene expression by HNF transcription factors. Science 303 1378-1381.

Ohmichi M, Koike K, Kimura A, Masuhara K, Ikegami H, Ikebuchi Y, Kanzaki T, Touhara K, Sakaue M, Kobayashi Y et al. 1997 Role of mitogen-activated protein kinase pathway in prostaglandin F2alpha-induced rat puerperal uterine contraction. Endocrinology $1383103-3111$.

Oldenhof AD, Shynlova OP, Liu M, Langille BL \& Lye SJ 2002 Mitogen-activated protein kinases mediate stretch-induced c-fos mRNA expression in myometrial smooth muscle cells. American Journal of Physiology, Cell Physiology 283 C1530-C1539.

Osman I, Young A, Ledingham MA, Thomson AJ, Jordan F, Greer IA \& Norman JE 2003 Leukocyte density and pro-inflammatory cytokine expression in human fetal membranes, decidua, cervix and myometrium before and during labour at term. Molecular Human Reproduction 9 41-45.

Otun HA, MacDougall MW, Bailey J, Europe-Finner GN \& Robson SC 2005 Spatial and temporal expression of the myometrial mitogen-activated protein kinases p38 and ERK1/2 in the human uterus during pregnancy and labor. Journal of the Society for Gynecological Investigation 12 185-190.

Ozaki H, Yasuda K, Kim YS, Egawa M, Kanzaki H, Nakazawa $\mathbf{H}$, Hori M, Seto M \& Karaki H 2003 Possible role of the protein kinase C/CPI-17 pathway in the augmented contraction of human myometrium after gestation. British Journal of Pharmacology $\mathbf{1 4 0}$ $1303-1312$

Papadopoulou N, Chen J, Randeva HS, Levine MA, Hillhouse EW \& Grammatopoulos DK 2004 Protein kinase A-induced negative regulation of the corticotropin-releasing hormone R1alpha receptor-extracellularly regulated kinase signal transduction pathway: the critical role of Ser301 for signaling switch and selectivity. Molecular Endocrinology 18 624-639.

Phaneuf S, Carrasco MP, Europe-Finner GN, Hamilton CH \& Lopez Bernal A 1996 Multiple G proteins and phospholipase C isoforms in human myometrial cells: implication for oxytocin action. Journal of Clinical Endocrinology and Metabolism 81 2098-2103.

Qi M \& Elion EA 2005 Formin-induced actin cables are required for polarized recruitment of the Ste 5 scaffold and high level activation of MAPK Fus3. Journal of Cell Science 118 2837-2848.
Rehman KS, Yin S, Mayhew BA, Word RA \& Rainey WE 2003 Human myometrial adaptation to pregnancy: cDNA microarray gene expression profiling of myometrium from non-pregnant and pregnant women. Molecular Human Reproduction 9 681-700.

Riley M, Wu X, Baker PN \& Taggart MJ 2005a Gestational-dependent changes in the expression of signal transduction and contractile filament-associated proteins in mouse myometrium. Journal of the Society for Gynecological Investigation 12 e33-e43.

Riley M, Baker PN, Tribe RM \& Taggart MJ 2005b Expression of scaffolding, signalling and contractile-filament proteins in human myometria: effects of pregnancy and labour. Journal of Cellular and Molecular Medicine 9 122-134.

Robin P, Boulven I, Desmyter C, Harbon S \& Leiber D 2002 ET-1 stimulates ERK signaling pathway through sequential activation of PKC and Src in rat myometrial cells. American Journal of Physiology, Cell Physiology 283 C251-C260.

Robin P, Boulven I, Bole-Feysot C, Tanfin Z \& Leiber D 2004 Contribution of PKC-dependent and -independent processes in temporal ERK regulation by ET-1, PDGF, and EGF in rat myometrial cells. American Journal of Physiology, Cell Physiology 286 C798-C806.

Romero R, Kuivaniemi H \& Tromp G 2002 Functional genomics and proteomics in term and preterm parturition. Journal of Clinical Endocrinology and Metabolism 87 2431-2434.

Ruzycky AL 1998 Down-regulation of the mitogen-activated protein kinase cascade immediately before parturition in the rat myometrium. Journal of the Society for Gynecological Investigation $\mathbf{5}$ 304-310.

Salomonis N, Cotte N, Zambon AC, Pollard KS, Vranizan K, Doniger SW, Dolganov G \& Conklin BR 2005 Identifying genetic networks underlying myometrial transition to labor. Genome Biology 6 R12.

Sehringer B, Zahradnik HP, Simon M, Ziegler R, Noethling C \& Schaefer WR 2004 mRNA expression profiles for corticotrophinreleasing hormone, urocortin, $\mathrm{CRH}$-binding protein and $\mathrm{CRH}$ receptors in human term gestational tissues determined by realtime quantitative RT-PCR. Journal of Molecular Endocrinology 32 339-348.

Shen Y, Iqbal J, Xiao L, Lynch RC, Rosenwald A, Staudt LM, Sherman S, Dybkaer K, Zhou G, Eudy JD et al. 2004 Distinct gene expression profiles in different B-cell compartments in human peripheral lymphoid organs. BMC Immunology 520.

Shynlova O, Tsui P, Dorogin A, Chow M \& Lye SJ 2005 Expression and localization of alpha-smooth muscle and gamma-actins in the pregnant rat myometrium. Biology of Reproduction 73 773-780.

Shynlova O, Oldenhof A, Dorogin A, Xu Q, Mu J, Nashman N \& Lye SJ 2006 Myometrial Apoptosis: Activation of the Caspase Cascade in the Pregnant Rat Myometrium at Midgestation. Biology of Reproduction [in press].

Sooranna SR, Lee Y, Kim LU, Mohan AR, Bennett PR \& Johnson MR 2004 Mechanical stretch activates type 2 cyclooxygenase via activator protein-1 transcription factor in human myometrial cells. Molecular Human Reproduction 10 109-113.

Stein RC \& Waterfield MD 2000 PI3K inhibition: a target for drug development? Molecular Medicine Today 6 347-357.

Tashima LS, Yamamoto SY, Yasuda M, Millar LK \& Bryant-Greenwood GD 2002 Decidual relaxins: gene and protein up-regulation in preterm premature rupture of the membranes by complementary DNA arrays and quantitative immunocytochemistry. American Journal of Obstetrics and Gynecology 187 785-797.

Tierney EP, Tulac S, Huang ST \& Giudice LC 2003 Activation of the protein kinase A pathway in human endometrial stromal cells reveals sequential categorical gene regulation. Physiological Genomics 16 47-66.

Wang H \& Hirsch E 2003 Bacterially-induced preterm labor and regulation of prostaglandin-metabolizing enzyme expression in mice: the role of toll-like receptor 4. Biology of Reproduction 69 1957-1963.

Wang Y, Matsuo H, Kurachi O \& Maruo T 2002 Down-regulation of proliferation and up-regulation of apoptosis by gonadotropin- 
releasing hormone agonist in cultured uterine leiomyoma cells. European Journal of Endocrinology 146 447-456.

Williams SJ, White BG \& MacPhee DJ 2005 Expression of alpha5 integrin (Itga5) is elevated in the rat myometrium during late pregnancy and labor: implications for development of a mechanical syncytium. Biology of Reproduction 72 1114-1124.

Wong DJ \& Chang HY 2005 Learning more from microarrays: insights from modules and networks. Journal of Investagative Dermatology 125 175-182.

Wu WX, Zhang Q, Ma XH, Unno N \& Nathanielsz PW 1999 Suppression subtractive hybridization identified a marked increase in thrombospondin-1 associated with parturition in pregnant sheep myometrium. Endocrinology 140 2364-2371.

Yu JT \& Lopez Bernal A 1998 The cytoskeleton of human myometrial cells. Journal of Reproduction and Fertility 112 185-198.
Zhong M, Yang M \& Sanborn BM 2003 Extracellular signal-regulated kinase $1 / 2$ activation by myometrial oxytocin receptor involves Galpha(q)Gbetagamma and epidermal growth factor receptor tyrosine kinase activation. Endocrinology 144 2947-2956.

Zhong M, Ku CY \& Sanborn BM 2005 Pathways used by relaxin to regulate myometrial phospholipase C. Annals of the New York Acadamies of Science 1041 300-304.

Received 21 December 2005

First decision 13 January 2006

Revised manuscript received 23 February 2006

Accepted 7 March 2006 